\title{
Hobbes En SinAloa, o DEL CORRIDO COMO RESOlUCión POÉTICA A UN ORDEN SOCIAL MARCADO POR LA VIOLENCIA
}

\author{
María Luisa de la Garza Chávez
}

Resumen: Este artículo muestra cómo una veta de la producción actual de corridos constituye una forma tan innovadora como radical de actuar frente a una realidad social que tiene mucho en común con el «estado de naturaleza» que Hobbes imaginó como causante del primer pacto político de la historia de la humanidad. En el México de hoy, en el que no se observa otra cosa que el fracaso de la política, la única opción para garantizar la conservación de sí parece radicar en la poética.

Palabras clave: México, violencia, corridos

Enviado a dictamen: 10 de octubre de 2008

Aprobación: 27 de noviembre de 2008.

Dra. María Luisa de la Garza, doctora en filosofía por la Universidad Autónoma de Madrid, es profesora-investigadora del Centro de Estudios Superiores de México y Centroamérica, de la UNICACH. Forma parte del cuerpo académico "Sociedad y Cultura en Fronteras". Áreas de investigación: ética y hermenéutica, análisis del discurso, antropología cultural, músicas populares. Correo electrónico: mluisa_delagarza@yahoo.es.
Abstract: This paper shows how a vein in the production of modern Mexican folk ballad constitutes an innovative, yet radical, course of action against a violent social reality. This social reality has many similarities with the state of nature that Hobbes envisioned as the reason for the first social contract in human history. In contemporary Mexico, where only political failures are found, the only way to guarantee self preservation seems to be poetics.

Key words: Mexico, violence, folk ballad

$\mathrm{D}$ ecía Thomas Hobbes en su célebre obra Leviatán (165l) que en el «estado de naturaleza» en el que vivían los seres humanos antes de que hubiera autoridad ninguna existía una situación de guerra de todos contra todos en la que dominaban tres «pasiones primitivas»: la competencia, la desconfianza y el deseo de gloria. En esa situación imaginada como original, cada persona era un depredador en potencia de todas las demás, idea que sintetiza en su célebre frase: homo homini lupus. Según su teoría, el deseo de cada cual de tener garantizada la conservación de sí mismo lleva a los seres humanos a negociar y a ponerse de acuerdo sobre la forma de conseguir que haya paz, para no tener que temer de todo y de todos. De esta manera, se llega a un contrato social por el que cada uno renuncia a tratar 
de conseguir por cualquier medio todo aquello que le apetezca y, al mismo tiempo, se compromete a no ejercer la libertad de impedirle a los otros ese mismo derecho, es decir, renuncia a su poder absoluto y se compromete a no aniquilar a los demás. Para garantizar la paz, cada persona «natural» cede su poder absoluto propio a una personalidad «de segundo grado», a una persona «ficticia» o «artificial» que lo representará: un soberano o una asamblea, es decir, el Estado.

Leo Strauss, lector de Hobbes, escribió allá por 1936 que detrás del «estado de naturaleza» planteado por el filósofo inglés había una antinomia más fundamental, una «antinomia originaria» compuesta, de una parte, por la vanidad, y, de otra parte, por el miedo a la muerte violenta. Según este filósofo alemán que se radicó en Estados Unidos huyendo de los nazis y cuyo pensamiento hoy enarbolan los neoconservadores norteamericanos, todo ser humano encuentra gran placer en imaginarse en una posición de superioridad a partir de la cual todos los demás le teman y le obedezcan. ${ }^{1}$

Pues bien, a tres siglos y medio de aquella obra fundadora de la filosofía política moderna, y en un México donde incluso los representantes políticos adolecen de las tres pasiones primitivas que caracterizaban el «estado de naturaleza» hobbesiano, en el noroeste del país ha surgido una insospechada resolución a la situación que se vive de miedo y de violencia: deslegitimado como está el Estado y sabedores de los fines que normalmente persiguen los pactos políticos, la persona ficticia a la que cada uno cede su poder absoluto no es simplemente una personalidad «de segundo grado», sino literalmente - literariamente - un personaje de ficción: el personaje de su corrido particular, en una estrategia de corte poético por la que cientos — tal vez miles- de individuos buscan hacerse notables y, dado el caso, sobrevivir.

Nos referimos a esos corridos que algunos investigadores llaman «de amistad» y que otros, enfatizando que su intención primera no es comercial, llaman «privados» -aun cuando también sean públicos. No están desti- nados, en principio, a los medios de difusión masiva, sino que están hechos para ser cantados en directo en ámbitos donde los protagonistas puedan sentir un reconocimiento que quizá de algún modo compense los riesgos que sus vidas corren. Forman parte, por supuesto, de esa categoría de corridos «de personaje» que dan testimonio de una vida cuyas virtudes, cuyas acciones o cuya excepcionalidad - cualquiera que sea - la hacen memorable, pero que no surgen de la iniciativa espontánea de algún trovador o de un improvisado poeta que se pone a componer por admiración o asombro, sino que son elaborados por encargo.

La tradición de este tipo de corridos es larga. Podemos referirnos a los panegíricos hechos a modo para promocionar a algún candidato a elección de representación popular, o remontarnos a los músicos que acompañaban a algunos generales revolucionarios, cuyo trabajo consistía menos en relatar desde un punto de vista imparcial el desarrollo de acontecimientos relevantes, que en difundir la versión de los hechos de acuerdo con la interpretación que de los mismos hiciera aquél a quien servía o el grupo al que acompañaba. Algunos estudiosos llegan incluso a vincular directamente estos corridos con el romance vulgar, que también era hecho y difundido por encargo. Magdalena Altamirano, por ejemplo, al explicar el carácter mercantil que ambos comparten, señala que:

El romance vulgar es un tipo de poesía popular difundido a través del pliego suelto. Este vínculo con la venta de impresos populares y su transmisión mediante la actividad de un transmisor profesional -el ciego recitador y, a veces, creador o refundidorhace que el romance vulgar posea características muy especiales e íntimamente relacionadas con los propósitos comerciales de sus creadores, impresores y transmisores. ${ }^{2}$

Hoy en día, se trata principalmente de canciones hechas por conocidos de los protagonistas, a quienes éstos les 
indican qué datos deben incluir y cómo desean ser representados. Después, si el compositor no es cantante o el cliente prefiere a otro intérprete, busca al vocalista y a los músicos que desea que se lo graben y obtiene una maqueta, de la que el estudio saca las copias que desee. Entonces, ya sea como grabación independiente o como parte de un disco que los músicos elaboran con ése y otros materiales similares, el protagonista reparte su historia entre sus amigos, y probablemente pague también para que el grupo «de planta» de su local favorito se lo aprenda y lo toque siempre que él esté presente.

Con frecuencia, los compositores no son profesionales, de manera que la calidad literaria puede no ser muy notable, y aunque quienes los graben sea gente que se dedica a la música, la calidad de los intérpretes y de los recursos técnicos utilizados en la producción puede ser muy desigual. ${ }^{3}$ Pero nada de ello importa si se cumple el objetivo de tener un corrido propio para poder presumírselo a familiares y amigos. Porque es probable que Gilles Lipovetsky tenga razón cuando dice, en Laera del vacío, que en nuestros días la lucha por el reconocimiento social no ha desaparecido, sino que se ha «privatizado», manifestándose principalmente en circuitos íntimos: «el deseo de reconocimiento-dice-ha sido colonizado por la lógica narcisista, se vuelve cada vez menos competitivo, cada vez más estético, erótico, afectivo». ${ }^{4}$

Bien es verdad que, a diferencia de lo que ocurre en Europa, donde domina sin adversarios la tendencia psi (esa que eleva a máximos valores la realización personal íntima y el respeto a la singularidad subjetiva), en México — como probablemente en otros países marcados por desigualdades sociales similares-, la competitividad no disminuye, sino que se inserta en la propia lógica esteticista y afectiva. ${ }^{5}$ Para el caso de México y los corridos, estas composiciones son, en sí mismas, motivo de prestigio y de pugna. Sirva la historia de (y en torno de) Lamberto Quintero como paradigmático ejemplo:

Se trata de un narcotraficante no muy relevante que murió asesinado en 1976. Era miembro de una familia de Badiraguato que tenía un añejo - y en ocasiones sangriento- - litigio con otra familia (los Lafarga, de San Ignacio), litigio que había comenzado con un primer homicidio ocurrido en 1971 - al parecer accidentalmente- - Dos días después de la muerte de Lamberto, las dos familias y sus pistoleros se enzarzaron en una balacera en el centro de Culiacán, en la que más de veinte personas murieron, entre ellas, los miembros que quedaban vivos del clan Lafarga. A petición de los deudos de Lamberto, Paulino Vargas le escribió un corrido, pero otro compositor que era primo de los rivales hizo lo propio con la historia de "Chito» Lafarga. Dicen que los dos corridos eran muy buenos, pero el de Chito Lafarga no se ha podido escuchar porque los Quintero prohibieron su difusión. En cambio, el corrido de Lamberto fue grabado nada menos que por Antonio Aguilar, y luego se hizo una película con «su vida». Como señala Helena Simonett en su libro Banda. Mexican musical life across borders, «el exitoso silencio impuesto sobre el corrido de Lafarga por el clan de los Quintero no sólo muestra cómo trabajan las fuerzas hegemónicas en la subcultura [del narcotráfico], sino que resalta la función tan significativa que el corrido tiene en esa subcultura». 6

Pues bien, Lamberto Quintero es, hoy, mucho más el personaje de su corrido que lo que realmente fuera en vida. A nivel popular, se le suele incluir en la lista de los narcotraficantes que en algún momento fueron poderosos, aunque en realidad nunca lo haya sido; y esto es así porque su corrido, que ha sido y sigue siendo grabado por distintos cantantes, ha afianzado la creencia de que era "un hombre fuera de serie [que] hace falta en Culiacán" (Lamberto Quintero). De hecho, quizá su vida ya es otra porque, tuviera o no descendencia, hay por ahí un hijo «suyo», El hijo de Lamberto Quintero, que clama venganza por la muerte de su padre y que agranda su leyenda de hombre noble supuestamente añorado por los pobres.

Sea, pues, por la exageración de las «hazañas» de los protagonistas, por los efectos de la mercadotecnia o por el resultado de luchas que también se libran en el plano del capital simbólico, la fama que algunos corridos 
proporcionan a sus protagonistas es tan inmerecida como duradera, y en este sentido la resolución poética que los corridos aportan a la «antinomia originaria» es innegablemente eficaz.

El corrido de Kiki Urías, compuesto también a raíz de la muerte de la persona a la que así llamaban, indica de forma explícita lo que aquí planteamos al señalar que la canción compuesta en su honor "cuidará de su vida"; cuidado que — suponemos- se ejercerá siempre que, con cada nueva interpretación del corrido, esa vida sea evocada. La narración comienza en el momento del asesinato del protagonista; se nos brindan, después, algunos datos de su biografía ("Nació en mero Culiacán, pero vivía en Tijuana; luego le dio por cruzar a la Unión Americana; como todo sinaloense, ya sabrán en lo que andaba"); luego, en unos cuantos versos, conocemos su ascenso «profesional» hasta el momento inmediatamente anterior a su muerte, cuando, en un imperdonable y trágico exceso de confianza, bajó la guardia: "Cuando regresó a Tijuana la muerte ya lo seguía, pero él no se imaginaba, por eso ni arma traía. Si lo hubiera sospechado, muertos otros estarían".

Las siguientes estrofas son el inicio del corrido, y recogemos también la estrofa final, donde se expresa, con toda la conciencia metalingüística a que ha lugar, la posible resolución poética a un ambiente donde nadie, en ningún lugar, tiene garantías de seguridad:

Se oyeron unas descargas de puros cuernos de chivo la gente salió corriendo a ver qué había sucedido; dos hombres estaban muertos y corrían los asesinos.

Enrique Urías, el Kiki, así todos le decían, en compañía del Moloco a tiros los abatían a unos pasos de su casa cuando en su troca salían. Por qué mataron al Kiki, todos hemos preguntado; no tenían cuentas con nadie, era hombre muy apreciado;

tal vez sería por envidia de los dueños del mercado.

\section{(...)}

Sus primos y sus hermanos, hijos, esposa y familia, toditos te recordamos; tus amigos, ni se diga,

y los Tigrillos te cantan; tu canción cuida tu vida.

Muchos corridos «privados» se hacen para honrar la memoria de alguien que ya falleció, pero los corridos que podríamos considerar específicamente como «de amistad» sirven para afianzar positivamente la identidad social de una persona, lo que significa, por un lado, posicionarse con fuerza (al menos aparentemente) frente a los enemigos que lo amenazan y, por otro lado, ver satisfecha su vanidad. El corrido de Rigo Coria es claro en cuanto a esta funcionalidad pre mortem del género. De acuerdo con el narrador de la historia, el protagonista:

En vida quiere el corrido para poder escucharlo tomando con sus amigos; quiere a la vez disfrutarlo y también pa' que se piquen los que han querido tumbarlo.

Algo similar se dice en el corrido de Eleazar Quintero:

Por el filo de la sierra, bonitos se ven los pinos; su servidor le canta el corrido a un gallo fino; quiere escucharlo con vida, tomando un trago de vino.

El narrador del corrido de Joaquín Santana ubica este tipo de trabajo discursivo en la larga tradición corridística mexicana, aunque también explicita el sentido particular de su canto, al decir:

No voy a hablar de tragedias ni de difuntos famosos, el corrido lo dedico al buen hombre de negocios que quiere escucharlo en vida para sentirse orgulloso.

Helena Simonett, que ha estudiado algunas de las dinámicas sociales en que se insertan estos corridos, nos habla de «micromundos» donde realidad y ficción 
se intersectan, desafiándose y al mismo tiempo reforzándose. Los clubes nocturnos de Los Ángeles son los lugares que ella ha estudiado, pero lo mismo ocurre en algunas cantinas de Sinaloa y de otros estados del país. Ahí, de cuando en cuando aparecen determinados individuos que difícilmente pasan inadvertidos para cualquier asistente más o menos atento a lo que ocurre a su alrededor, y esto es así no sólo por su manera de vestir, por los oros que llevan o el precio de las bebidas que consumen, sino por su relación con los músicos y su actitud cuando éstos cantan determinadas canciones.

Según descripciones etnográficas como las que esta investigadora presenta en "The Corrido of Ramón R." se puede decir que esas personas incluso determinan el repertorio de los músicos. En la velada descrita en este texto, El corrido de Ramón R. -indudablemente referido a la persona que en la mesa «reservada» se echa para atrás en su silla cuando lo tocan y que lo escucha siempre con aire de satisfacción- fue cantado tres veces ese día, tantas como la canción que en el corrido se dice que es su favorita. Pero no sólo eso,

Ya entrada la noche, el vocalista de la banda del local canta otros corridos hechos por encargo. Uno, dedicado a Walter R. — hermano de Ramón - y otro a Higinio, amigoy guardaespaldas de Ramón que también estápresenteesta noche. Con estos corridos, conocemos algunos detalles más de [su] vida concreta e imaginada. ${ }^{8}$

Estas historias de vida, al menos en su versión imaginada, no pueden menos que evocarnos a Hobbes y su «estado de naturaleza», pues plasman continuamente una situación casi de guerra de todos contra todos, donde la amenaza siempre está presente y lo único seguro es la muerte, acaecida muchas veces, en efecto, de forma violenta. Sirvan de ejemplo los corridos de Prajedes Félix y de Armando Aguirre:

Nacido allá en Chapotal, después vivió en Agua Blanca, entre pura gente brava, entre escuadras y la banda; Prajedes Félix se llama; no cualesquiera lo ablanda. (...) Por las buenas, muy sincero, como un diablo de enemigo; hay unas cruces clavadas que me sirven de testigos. Prajedes Félix

Tengo un contrato firmado desde que vine a este mundo; no le pusimos la fecha, por eso es que vivo a gusto; el mundo da muchas vueltas y yo de nada me asusto. Con la muerte por un lado, todo el tiempo me paseo; no me gusta presumir, pero no me miren feo: ahí traigo un cuerno de chivo, no lo tengo de trofeo. Armando Aguirre

Como se observa, la desconfianza y la competencia están siempre presentes, pero habría que destacar que con frecuencia estas dos pasiones primitivas aparecen sintetizadas en (o activadas por -y quizá éste sería el rasgo diferencial de un estado de naturaleza hobbesiano a la mexicana) otra pasión que no es menos inmemorial: la envidia.

En efecto, la única hipótesis apuntada para explicar la muerte del Kiki Urías era "la envidia de los dueños del mercado", e igualmente en el caso de Rigo Coria, "los que han querido tumbarlo" aparecen dominados por este primitivo sentimiento, según se dice en otro pasaje de su corrido:

Trae una cuarenta y cinco para todo el envidioso; él nunca busca problemas, pero está muy orgulloso; siempre pelea frente a frente, la espalda es pa'l ventajoso.

En estas historias de vida no está menos presente el deseo de gloria, en cuya satisfacción los corridos desempeñan un papel muy importante. Literal y metafóricamente hablando, tienen mucho que decir; de manera que en el proliferar de historias ocurre que hay momentos 
en los que no sabemos si la fama de algún personaje se debe a la relevancia de sus acciones, o a la circulación del relato de las mismas en forma de corrido. Es lo que sucede, por ejemplo, ante un personaje como aquél al que llaman «El Grande»:

El corrido que hoy les canto se lo compuse a un amigo,

su nombre es Rigo Fuentes, por "El Grande" conocido,

y es uno de los valientes que en Michoacán han nacido.

En Texas y en California también conocen su historia,

y allá por Apatzingán, pueblo que le dio la gloria, siempre lo han de recordar por su grande trayectoria.

Corrido de El Grande

Muchos de estos corridos «de amistad» fueron compuestos por Chalino Sánchez, a quien puede considerarse, si no el creador del subgénero, sí el que lo promoviera y quien le daría el impulso definitivo -icómo no! — con su muerte violenta, ocurrida en 1992, después de haber ofrecido un concierto. ${ }^{9}$ Su carrera fue corta, pero de gran repercusión: a fines de los años 80 vendía en la calle los cassettes que él mismo grababa con corridos que les había compuesto a algunos narcotraficantes de poca monta en Los Ángeles. Después, comenzó a dar pequeños conciertos hasta que en uno de ellos ocurrió un tiroteo - con él, pistola en mano, defendiéndose desde el escenario- que hizo que verdaderas multitudes acudieran después a verlo en sus actuaciones.

Como ha escrito Lucila Lobato, en muchos corridos de Chalino «no existe propiamente una anécdota o historia que contar», pues se dedican sobre todo a exaltar las virtudes del protagonista. Esto, agrega, no quiere decir que dejen de ser corridos ni que no mantengan rasgos épico-narrativos, sino que su propósito de halagar a su cliente los obliga a ser más descriptivos que narrativos: lo único que ocurre, dice, es que «se acercan genéricamente a un tipo de creación lírica». ${ }^{10}$ Estando de acuerdo con esta valoración, nos gustaría, sin embargo, apuntar la hipótesis - más acorde con la tesis que aquí sostenemos- de que lo anecdótico es nada menos que vivir: lo reseñable es permanecer con vida.

La conciencia de finitud que se tiene en estos ambientes y regiones de México, unida al narcisismo propio de nuestra época tardomoderna y a la consolidación del corrido como elemento de prestigio, ha dado lugar a que un número cada vez mayor de aficionados a esta música encarguen la elaboración de un corrido sobre sí mismos. Según Helena Simonett, en el Nuevo Los Ángeles «cualquiera con un excedente económico de setecientos dólares encarga una canción que refleje su propio mundo imaginado», ${ }^{11}$ y no son muy distintas las cifras que brindan otros investigadores. De hecho, puede suceder que si algún narcotraficante de poca importancia e incontrolables impulsos desea tener la «prueba material» de sus hazañas pero no conoce a ningún letrista, se le ocurra «retener» a alguno por la fuerza, como le ocurrió a un director de una compañía de discos, según cuenta Elijah Wald en su libro Narcocorrido. Un viaje al mundo de la música de las drogas, armas y guerrilleros. ${ }^{12}$

Los propios cantantes, por su parte, deben estar alertas para que, agradando a unas personas, no incomoden a otras. El As de la Sierra ha dicho sobre esto:

Es algo muy bonito mi carrera, para mí; pero muy peligroso también. No nada más es subirse a cantar arriba. Mi público es un público, cómo le diré, un público de narcotraficantes. No todos; o sea, hay gente que tiene ilusión de ver a El As de la Sierra, de conocerlo, pero en mi público todo el tiempo va a haber gente del negocio (así le llamo yo). Entonces (...) yo puedo componerle un corrido a usted y usted tiene un enemigo [al] que no le parece y puede acarrearme problemas hacia mí. O sea, esto no es un juego, es algo delicado. Yo tengo que llevarme gente que me esté cuidando, ya que no falta. ${ }^{13}$ 
Ni la vanidad ni el temor a vivir una muerte violenta son aquí, como se ve, figuras retóricas. De hecho, muchos compositores que han conseguido cierto progreso económico cada vez prefieren más que sus corridos «bravos» sean ficticios, de manera que no pueda identificarse explícitamente a ninguna persona. Un productor de Badiraguato le explica a Wald cómo él, personalmente, se evita problemas:

Se hace un corrido que a cualquiera le puede quedar. Por ejemplo, yo compuse un corrido que se llama El chacal de chacales. Ese corrido no es de nadie. Dice: "Soy el chacal de chacales", y se habla de que es valiente, que las puede, de todas, todas. A cualquiera le puede quedar el corrido, y ahora dicen muchos: "Me queda muy bien a mí ese corrido. Es mío". Entonces, eso motiva a la gente y le gusta, y no va comprometiendo a nadie. ${ }^{14}$

Lamentablemente, una vez que se ha puesto a circular un corrido, quien lo compuso o lo grabó ya no tiene ningún poder sobre las resignificaciones que de él se hagan, y aquí vale recordar que una de las versiones sobre las causas de la muerte de Valentín Elizalde (asesinado el 25 de noviembre del 2006) es que su canción A mis enemigos fue utilizada como fondo musical de un video publicado en el portal de Youtube, que contenía una secuencia de fotografías de personas asesinadas, las cuales al parecer fueron ejecutadas por el cártel de Sinaloa. De acuerdo con la periodista Leonarda Reyes, esto pudo haber enfurecido al cártel del Golfo, organización a la que pertenecían varios de los asesinados incluidos en el video, y lo mandó matar..$^{15}$ La posibilidad de que esto sea cierto significaría que los asesinos de «El Gallo de Oro» idearon la sofisticada venganza de infligir a sus enemigos la pena, no de sufrir en sus propias carnes ningún dolor, sino de impedirles para siempre el gozo de disfrutar en directo a quien suponen que es uno de sus cantantes favoritos. El golpe a los adversarios va dirigido a la esfera de lo simbólico, aunque esto no disminuye la evidencia de que estarían actuando movidos por un sentimiento que combina la vanidad herida y la competencia: los celos, bien sea porque les doliera que Elizalde cantara para sus enemigos, bien porque pensaran que la letra de la canción en cuestión hiciera demérito de ellos.

En todo caso, es notable la fuerza — casi la preeminencia- del mundo ficcional/virtual, ya que, si nos fiamos de lo que circuló en lo que Leonarda Reyes llama los «narco-blogs», si los miembros del cártel del Golfo hubieran averiguado cuál era en realidad la relación de Valentín Elizalde con el cártel de Sinaloa, se habrían dado cuenta de que no había tal, y que no la había en parte porque los de esta organización sabían que solían contratarlo los del cártel del Golfo. «Se equivocaron - escribe uno de los narcotraficantes o pistoleros internautas-; mataron a gente inocente», lo que no le impide a este grupo «amenazar con cobrarse "ojo por ojo" y asesinar al cantante Beto Quintanilla», uno de los corridistas más queridos en el sector nororiental de la frontera. ${ }^{16}$

Como se ve, las razones por las que puede morir violentamente un compositor de corridos o un cantante no parecen ni muy diferentes ni menos numerosas que las que pueden acabar con la vida de un narcotraficante. Según uno de los innumerables corridos dedicados a Chalino Sánchez, "alguien lo mandó matar por envidia, porvenganza o un coraje pasional" (La muerte de Chalino). Sin duda, otros nombres para la competencia, la vanidad y la desconfianza.

\section{Notas}

${ }^{1}$ Leo Strauss; La filosofía política de Hobbes. Su fundamento y su génesis, Fondo de Cultura Económica, $1^{a}$ edición, Argentina, 2006.

2 Altamirano, Magdalena; El corrido mexicano actual: confluencia de elementos y posibilidades de apertura. Tesis inédita presentada en la Facultad de Filosofía y Letras de la UNAM en 1990, p. 46. Citada por Lucila Lobato en "Chalino Sánchez: corridos de personaje", artículo 
publicado en la Revista de Literaturas Populares, Año III, Núm. 1, enero-junio de 2003, p. 89.

${ }^{3}$ Este rasgo, por cierto, también lo compartirían con los romances vulgares, que serían vulgares -según explica Magdalena Altamirano- no tanto por «los niveles socioeconómicos y culturales del público, sino [debido] a su condición de producto comercial, la cual determina: la participación e improvisación de autores de muy diversos tipos y aptitudes; el esfuerzo de autores e impresores por responder a la demanda y llamar la atención al público mediante lo novelesco, incitante y desmesurado (que muchas veces se traduce en sensacionalismo y tremendismo); su producción masiva, en comparación con los textos cultos o tradicionales, que hace difícil la depuración artística y propicia, en cambio, el uso exhaustivo y poco creativo de argumentos, esquemas, fórmulas y tipos fijos». M. Altamirano, citada por Lucila Lobato, op. cit., p. 90.

${ }^{4}$ Gilles Lipovetsky, La era del vacío. Ensayos sobre el individualismo contemporáneo, Ed. Anagrama, col. Compactos, Barcelona, 2006, p. 71.

${ }^{5}$ Pienso, por ejemplo, en el auge que desde hace ya varios lustros tienen, como en ninguna otra región, las cirugías estéticas en países de Latinoamérica como Brasil o Colombia.

${ }^{6}$ Helena Simonett, Banda. Mexican musical life across borders, Wesleyan University Press, Middletown, Connecticut, 2001, p. 227.

${ }^{7}$ La descripción se incluye en el artículo "Narcocorridos: An Emerging Micromusic of Nuevo L. A.", publicado en Ethnomusicology, vol. 45, $\mathrm{N}^{\circ}$ 2, primavera-verano, 2001, pp. 315-337.

${ }^{8}$ Ibid., p. 329

${ }^{9}$ Rosalino (Chalino) Sánchez fue secuestrado el 15 de mayo de 1992 por supuestos policías vestidos de civil, y su cadáver fue hallado al día siguiente con cuatro balazos. El caso, que se atribuye a rencillas entre grupos de narcotraficantes, hasta hoy no ha sido resuelto. En su honor se dice que se han compuesto alrededor de 150 corridos.
${ }^{10}$ Lucila Lobato, "Chalino Sánchez: corridos de personaje”, en Revista de Literaturas Populares, Año III, Núm. l, enero-junio de 2003, p. 94.

${ }^{11}$ En "Narcocorridos: An Emerging Micromusic... art. cit., p. 330.

${ }^{12}$ Elijah Wald; Narcocorrido. Un viaje al mundo de la música de las drogas, armas y guerrilleros, HarperCollins, col. Rayo, Nueva York, 2001, p. 97.

${ }^{13}$ En conversación con Elijah Wald, recogida en Narcocorrido..., op. cit., pp. 95-96.

${ }^{14}$ Ibid., p. 101.

${ }^{15}$ Leonarda Reyes; "Los «narco-blogs»", en Proceso, número 1573, 24 de diciembre de 2006, pp. 16-17.

${ }^{16}$ Beto Quintanilla murió, efectivamente, a los pocos meses (el 19 de marzo del 2007), pero al parecer murió de muerte natural (de un infarto), lo que no puede decirse de otros cantantes que fallecieron en el mismo año, como Javier Morales (de Los Implacables del Norte), Sergio Gómez (del grupo K-Paz de la Sierra), Zayda Peña (del grupo Zayda y Los Culpables) y cuatro integrantes de la Banda Fugaz. Ahora bien, hay que señalar que, salvo en el caso de los dos primeros, en los repertorios de los demás grupos no predominaban los corridos «pesados», lo que únicamente indica lo extendido del «estado de naturaleza» hobbesiano.

\section{Bibliografía}

Hobbes, Thomas; 1992, Leviatán. O la materia, forma y poder de una república eclesiástica y civil, Alianza Editorial, España.

Lipovetsky, Gilles, 2007; La era del vacío. Ensayos sobre el individualismo contemporáneo, Ed. Anagrama, col. Compactos, $5^{\text {a }}$ edición, Barcelona.

Lobato, Lucila; 2003, "Chalino Sánchez: corridos de personaje”, en Revista de Literaturas Populares, año III, núm. 1, pp. 87-116.

Reyes, Leonarda; 2006, “Los «narco-blogs»”, en Proceso, número 1573 , pp. 16-17.

Simonett, Helena; 2001, Banda. Mexican musical life across borders, Wesleyan University Press, Middletown, Connecticut. 
-, 2001, "Narcocorridos: An Emerging Micromusic of Nuevo L. A.”, en Ethnomusicology, vol. 45, núm. 2, pp. 315-337.

Strauss, Leo, 2006, La filosofía política de Hobbes. Su fundamento y su génesis, Fondo de Cultura Económica, aa edición, Argentina.

Wald, Elijah, 2001, Narcocorrido. Un viaje al mundo de la música de las drogas, armas y guerrilleros, HarperCollins, col. Rayo, Nueva York.

\section{Referencias de los corridos citados}

"Armando Aguirre", de Chalino Sánchez, en Alma enamorada, Musart-Econolínea 2573, México, 2001.

"Corrido de El Grande", de Chalino Sánchez. Citado por Lucila Lobato en "Chalino Sánchez: corridos de personaje", artículo aparecido en la Revista de Literaturas Populares, año III, núm. 1, enero-junio de 2003, pp. 87 116.

“El corrido de Ramón R.", citado por Helena Simonett en "Narcocorridos: An Emerging Micromusic of Nuevo
L. A.”, artículo publicado en Ethnomusicology, vol. 45, núm. 2, primavera-verano, 2001, pp. 315-337.

"El hijo de Lamberto Quintero", de Mario Quintero Lara, en el disco de Pepe Aguilar, Éxitos con banda, MusartBalboa, 1626, México, 1996.

“Eleazar Quintero”, de Chalino Sánchez, en Corridos de los Félixy los Quintero, Balboa 2743, México, 2002.

"Joaquín Santana”, de Chalino Sánchez, en Chalino Sánchez cantando con sus amigos, Musart, México, 2001.

"Kiki Urías", de Mario Quintero Lara, recogida en interpretación de Los Tigrillos en México y su música. Los mejores corridos, 3 vols., Warner Music, 7502024, México, 2004.

"La muerte de Chalino", de José Quiñónez, recogida en interpretación de El Bronco de Sinaloa en A pura banda, vol. 2, EMI-Latin 28547, 1994.

"Lamberto Quintero", de Paulino Vargas, en 20 NarcoCorridos, de Los Huracanes del Norte.

"Prajedes Félix", de Chalino Sánchez, en Corridos de los Félixy los Quintero, Balboa 2743, México, 2002.

"Rigo Coria", de Chalino Sánchez, en Chalino Sánchez cantando con sus amigos, Musart, México, 2001. 